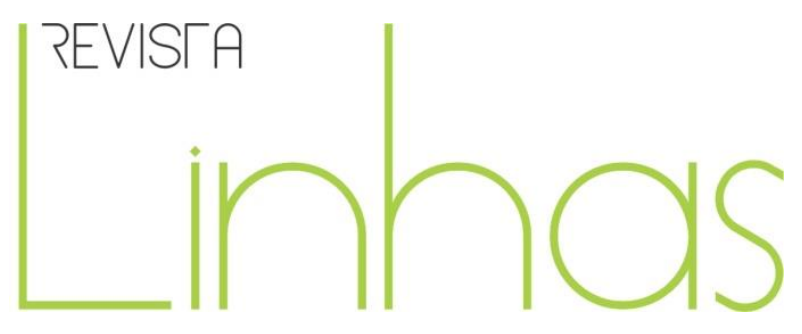

\title{
Resenha do livro "A nova Direita: aparelhos de ação política e ideológica no Brasil contemporâneo"
}

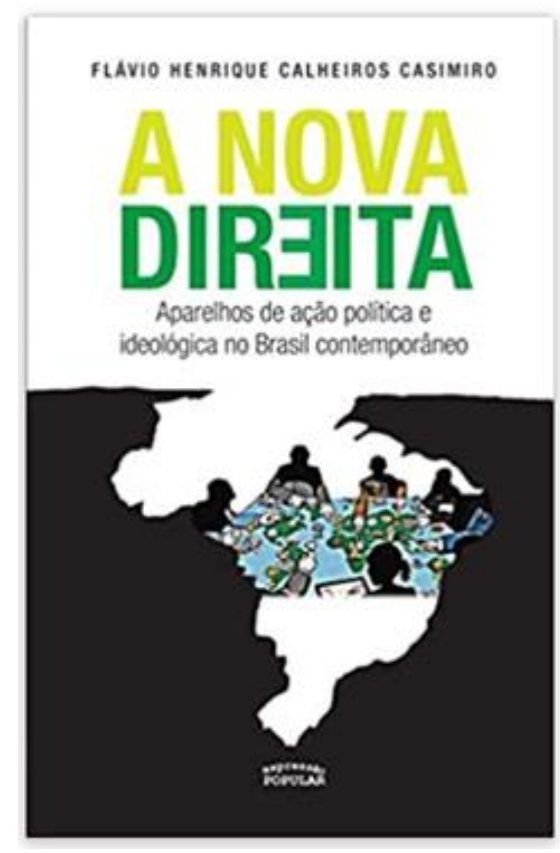

CASIMIRO, Flávio Henrique Calheiros. A nova Direita: aparelhos de ação política e ideológica no Brasil contemporâneo. 1 ed. São Paulo: Expressão Popular. 2018.

\section{Danilo Bandeira dos Santos Cruz}

Universidade Federal de Santa Catarina - UFSC - Brasil

danibande2@gmail.com

\section{Para citar esta resenha:}

CRUZ, Danilo Bandeira dos Santos. Resenha do livro "A nova Direita: aparelhos de ação política e ideológica no Brasil contemporâneo". Revista Linhas. Florianópolis, v. 21, n. 46, p. 352-358, maio/ago. 2020. 
Flávio Casimiro, doutor em História Social pela Universidade Federal Fluminense (UFF) e professor de História Econômica, Política e Social do Instituto Federal do Sul de Minas Gerais, na obra, objeto desta resenha, procura desenvolver uma reflexão acerca da sistemática forma de organização da burguesia brasileira em torno da renovação das suas estratégias de dominação e "atuação político-ideológica, a partir do processo de redemocratização do país, entre 1980 e 2014" (p. 17). Para tanto, o autor conduziu o seu percurso reflexivo com base no referencial teórico-metodológico de tradição marxista, do filósofo italiano Antonio Gramsci, cuja obra, apesar de fragmentada em razão das condições de sua elaboração - no âmbito de um cárcere - expressa uma profundidade e densidade fundamentais para a compreensão da dinâmica do Estado capitalista, elemento central na discussão posta em “A Nova Direita”.

De modo complementar, o livro em tela incorpora as valiosas contribuições teóricoanalíticas do importante historiador e cientista político uruguaio René Armand Dreifuss, o qual, com maestria, desenvolveu sólidas pesquisas acerca do Brasil contemporâneo e favoreceu a compreensão do metabolismo estatal no contexto da ditadura civil-militar, bem como do período ulterior, no âmbito do qual se consolidavam as disputas em torno da Assembleia Nacional Constituinte. Em tal contexto, Dreifuss demonstrava a forte presença de entidades da sociedade civil, de cunho empresarial, disputando entre si e com as representações da classe trabalhadora, a agenda política que conformaria o novo espaço-tempo da retomada da democracia brasileira, em vias de consolidação. Assim, de modo a atualizar tal reflexão, considerando o surgimento de uma multiplicidade de fatos históricos, Flávio Casimiro apontará as diferentes alterações ocorridas ao longo dos últimos trinta anos, demonstrando como as lutas de classes se mantiveram intensas e, ao mesmo tempo, foram atualizadas diante do processo de aprofundamento da socialização da política.

Nessa perspectiva, a particularidade do desenvolvimento da redemocratização do Brasil e os seus desdobramentos são postos em evidência, tendo em vista o alcance da clareza necessária para se compreender o contexto histórico de criação de um número expressivo de organizações privadas ligadas a grandes corporações empresariais, cujo sentido se volta, entre outros aspectos, à mediação dos interesses de classe, com atuação dirigida à produção do consentimento e, por conseguinte, ao exercício de dominação. 
Trata-se, portanto, dos caminhos traçados pelo bloco no poder para garantir a sólida construção de sua hegemonia.

O livro foi organizado em cinco capítulos, sendo que no primeiro deles, o autor concentra os seus esforços para analisar as formas de organização da burguesia, frente às disputas pela definição e direção do projeto de sociedade, a se consolidar na Constituinte, nos idos dos anos de 1987-1988. Revela-se, a partir da segunda metade dos anos 1970, os primeiros movimentos da burguesia no plano do complexo tabuleiro de xadrez da política, no sentido do estabelecimento de articulações interburguesas, sinalizando a preparação para a manutenção da hegemonia, diante da "transição da ditadura civil-militar para a Nova República" (p. 39).

Essas movimentações tiveram por corolário, a criação de um conjunto de instituições, representantes dos diferentes setores da economia, sobretudo na década de 1980, como por exemplo, a Confederação Nacional das Instituições Financeiras (CNF), a União Democrática Ruralista (UDR); a União Brasileira de Empresários (UB), o Pensamento Nacional de Bases Empresariais (PNBE), a Frente Nacional pela Livre Iniciativa (FNLI), entre tantos outros, citados e esquadrinhados por Casimiro ao longo do seu livro. Essas organizações protagonizaram um processo de espraiamento da sociedade civil, cada vez mais integrada ao Estado stricto senso, numa lógica marcada pelo desenvolvimento de uma extensa rede de aparelhos de ação política e ideológica ${ }^{1}$. Assim, entre associações e cisões, harmonias e conflitos interburgueses, algumas dessas organizações foram dissolvidas e outras mantidas e ampliadas, como sinal da preservação do seu poder de interferência nas decisões dos governos, em seus variados matizes ideológicos.

Na sequência de sua reflexão, o autor discute, no segundo capítulo, o processo de ampliação e ressignificação do papel do Estado, no âmbito do movimento de socialização da política, entre 1980-1990, cujos desdobramentos refletiram no aumento expressivo do número de Organizações Não Governamentais (ONGs), bem como de Fundações Privadas

\footnotetext{
${ }^{1} \mathrm{O}$ autor faz referência ao conceito gramsciano de "aparelhos privados de hegemonia" - APHs, cunhado para explicar as associações de classe ou frações de classe que se estabelecem no âmbito da sociedade civil, tendo em vista a disputa de projetos, capazes de representar as vontades coletivas que se pretendem constituir como prevalentes. Dessa forma, Casimiro, ao longo de toda a sua reflexão, vai apresentando ao leitor um amplo conjunto de entidades da sociedade civil brasileira, que cumprem a função de APHs, voltando-se à defesa dos interesses de uma "nova direita", estruturada no Brasil, a partir do seu processo de abertura à democracia.
} 
e Associações Sem Fins Lucrativos (FASFIL's), dispostas a absorverem muitas das funções atribuídas ao aparelho estatal. Nesse ponto, é revelada a captura dessas instituições por parte de "uma multiplicidade de organizações da classe dominante" (p. 121), comprometidas com a tarefa de promover o apassivamento e a absorção das lutas sociais, por intermédio da consolidação do convencimento. $O$ destaque é dado à atuação do Grupo de Institutos, Fundações e Empresas (GIFE) e o Instituto Ethos de Empresas e Responsabilidade Social, expressões do chamado “capitalismo humanizado". Conquanto, o sentido real dessa lógica de compromisso social se volta ao esforço de se naturalizar a ideologia neoliberal, numa perspectiva direcionada à universalização dessa forma particularizada de se perceber e se participar do mundo, isto é, plenamente alinhada aos pressupostos do livre mercado, mas projetada como concepção geral, de toda a sociedade. Isso ajuda a compreender, por exemplo, o fenômeno do consentimento ativo, capaz de levar os membros da classe que vive de sua força de trabalho à reprodução permanente da sua própria condição de subsunção ao capital e, nesse sentido, da intensa dinâmica de exploração a que estão submetidos, sem que, no entanto, esse processo seja, por tais homens percebido como histórico e, portanto, possível de ser superado.

Em face dessas complexas relações, uma série de reformas na estrutura institucional do Estado foram operacionalizadas, preponderantemente, ao longo da segunda metade da década de 1990, impulsionando a atualização das massivas formas de expropriações sociais. Uma dinâmica de alterações das estruturas econômicas e sociais brasileiras, associadas ao quadro mais ampliado de mundialização do capital, em sua etapa de imperialismo monopolista. Nesse cenário, as resistências sociais ao projeto neoliberal não foram ignoradas. O autor de A Nova Direita as sinaliza de modo a evidenciar as disputas entre as classes e o consequente retardamento das reformas liberalizantes, defendidas pelo bloco no poder daquele período.

No terceiro capítulo foram pesquisados o Instituto de Estudos para o Desenvolvimento Industrial (ledi), o Instituto Atlântico, o Grupo de Líderes Empresariais (Lide) e o Movimento Brasil Competitivo (MBC). A atuação desses aparelhos privados de hegemonia, financiados por grandes corporações empresariais nacionais e internacionais, se dirigiu para a manutenção e aprofundamento do conjunto de reformas implementadas pela sociedade política, cuja finalidade se mantinha no terreno dos interesses da 
perpetuação do poder de classe. Alterações constitucionais eram impostas como forma de se garantir a manutenção do controle dos fundos públicos por parte de uma minoria privilegiada, ao passo que se avançava no processo de destituição dos direitos sociais. Por essa via, entre os finais dos anos 1990 e início dos anos 2000, houve o crescimento exponencial do número de FASFILs, "ampliando assim a representatividade das classes dominantes na arena das lutas de classes no Brasil” (p. 152).

O quarto capítulo traz considerações fundamentais para se compreender as alterações promovidas nessa última quadra histórica, marcada pela ascensão de uma Direita liberal conservadora. Os representantes dessa "nova direita" se distribuem por diferentes aparelhos privados de hegemonia, como partidos políticos, veículos de comunicação, com destaque à internet, cada vez mais utilizada como estratégia políticoideológica; entidades patronais e, inclusive, universidades. Sistematicamente aliançados, porém, com atuações complementares - alguns órgãos agem mais no sentido doutrinário, enquanto que outros priorizam a formulação e realização de projetos de poder - esses intelectuais ${ }^{2}$ coletivos se impõem como definidores máximos da direção política do país, ignorando, quase que completamente, as amplas demandas das classes subalternas e agenciando os seus modos de agir-pensar. Nesse sentido, enfatizam-se as influências do Instituto Liberal (IL); o Instituto de Estudos Empresariais (IEE); o Fórum da Liberdade. O Instituto Milenium (Imil), o Instituto Von Misses Brasil (IMB); o Estudantes Pela Liberdade (EPL) e o seu par, Movimento Brasil Livre (MBL), "marca criada pelo EPL para participar das manifestações de rua sem comprometer as organizações estadunidenses", responsáveis por parte do financiamento dessas entidades, que pela "legislação da receita americana", eram “impedidas de doar recursos para ativistas políticos” (p. 402).

No quinto e derradeiro capítulo, o autor indica a participação complementar do Instituto Fernando Henrique Cardoso (iFHC) no movimento ampliado de internacionalização da burguesia brasileira, através do "desenvolvimento de estratégias que apontam para a organização de verdadeiras 'embaixadas’ de negócios e estruturação

\footnotetext{
${ }^{2} \mathrm{O}$ intelectual aqui, segundo o referencial gramsciano, carrega em si o sentido da capacidade de um sujeito ou grupo de sujeitos de exercer a direção de uma entidade social e não como o senso comum apreende, isto é, como intelectualismo, correspondente aos estudiosos, pessoas "cultas", filósofos, cientistas, doutos e que, em outros termos, podem muito bem ser representadas na figura épica do "Pensador", de Rodin. Sendo assim, conforme Gramsci, é possível afirmar que todos os seres humanos são intelectuais, muito embora nem todos exerçam o papel de intelectuais.
} 
de relações econômicas bilaterais" (p. 415). Nessa etapa da reflexão, a relação dialética entre sociedades política e civil volta a ser evidenciada, o que favorece o alcance da superação da visão fragmentada, produzida pela literatura de tradição liberal, a qual posiciona o Estado no campo privilegiado da dominação e do poder político, enquanto situa a sociedade civil no "espaço da produção e da liberdade dos indivíduos". Destarte, em sua tarefa de desvendar as formas de atuação das organizações empresariais, Flávio Casimiro demonstra como funciona o trânsito entre intelectuais orgânicos e agentes políticos no constante movimento de definição dos projetos de poder, materializados em reformas que atacam a classe trabalhadora e privilegiam, ainda mais, os interesses de reprodução e ampliação do capital.

Em síntese, é possível inferir que os principais objetivos das organizações, objeto de estudo do autor, são: 1. a reprodução da ideologia burguesa, principalmente, através da produção do consenso; 2. o combate às formas contrárias às concepções de mundo de cunho liberal; 3. a ampliação das taxas de acumulação a partir da reestruturação das funções do Estado; 4. além da projeção positiva da imagem das empresas que esses grupos representam e que se vinculam, aparentemente, às preocupações relativas às demandas gerais da sociedade, causando um importante impacto comercial, através da chamada "responsabilidade social".

Como se vê, o livro de Flávio Casimiro é uma obra atual, que vem corroborar as interpretações e compreensões atinentes à conjuntura econômica e política do Brasil, em tempos marcados pelo ascenso de uma Direita liberal conservadora e truculenta, cujas técnicas e estratégias se voltam à garantia da dominação, sobretudo, a partir da atuação de inúmeros aparelhos privados de hegemonia. Técnicas que têm sido postas em movimento desde o processo de redemocratização do país, como demonstra Casimiro, e que adquirem um caráter ainda mais incisivo no limiar da primeira década do século XXI, quando se verifica o transbordar de complexas tramas político-ideológicas, que tiveram por corolário, a própria eleição do presidente, agora sem partido, Jair Messias Bolsonaro. O discurso de ódio contra as minorias, os ataques às políticas sociais, a exaltação aos princípios do ultraliberalismo e o enfático combate às perspectivas progressistas, compõem o seu perfil mais evidente. 
Nesse direcionamento, essa "nova direita” tem avançado na implementação de um conjunto de reformas voltadas contra os interesses da classe trabalhadora, desarticulando e desestabilizando as suas lutas, historicamente constituídas, através de medidas que combinam força e consenso, as quais retiram direitos sociais e lançam centenas de milhares de pessoas na informalidade e na miséria. Aprofunda-se o abismo entre a riqueza e a pobreza, numa lógica de reprodução de uma intensa crise social, que se soma a da natureza, cada vez mais degradada, em razão do afrouxamento premeditado das ações de proteção ambiental, cujo sentido é o de garantir a ampliação da apropriação privada dos recursos naturais, privilegiando grandes proprietários rurais e mineradoras. Ademais, a democracia brasileira se vê constantemente ameaçada.

Destarte, o que se percebe na realidade concreta do Brasil contemporâneo é o avanço generalizado das forças que determinam o ordenamento social sob os moldes da propriedade privada, com uma participação crucial do Estado, seja através dos seus aparelhos governativos ou pela atuação, nos termos do autor, da engenhosa rede de aparelhos de ação política e ideológica, que se espraia no âmbito da sociedade civil. Nessa direção, o Estado passa a se conformar às novas demandas de reprodução capitalista. E isso se dá, por intermédio de permanentes reformas, anunciadas como necessidade fundamental para que as crises socioeconômicas sejam superadas e, com isso, o interesse da sociedade, em seu conjunto, possa ser alcançado. No campo concreto, essas conformações estatais não passam de estratégias renovadas para garantir a construção e perpetuação do domínio da burguesia nacional. Uma burguesia, que associada aos grupos empresarias dos países centrais, "mesmo que ocupando uma posição de 'sócio-menor"” (469), "busca expandir-se" indefinidamente, apoiada em um processo combinado de concentração de capitais e constantes expropriações. 
CASIMIRO, Flávio Henrique Calheiros. A nova Direita: aparelhos de ação política e ideológica no Brasil contemporâneo. 1 ed. São Paulo: Expressão Popular. 2018.

Recebido em: 26/03/2020

Aprovado em: 28/04/2020

Universidade do Estado de Santa Catarina - UDESC

Programa de Pós-Graduação em Educação - PPGE

Revista Linhas

Volume 21 - Número 46 - Ano 2020

revistalinhas@gmail.com 